\title{
(2) OPEN ACCESS \\ Concordance with urgent referral guidelines in patients presenting with any of six 'alarm' features of possible cancer: a retrospective cohort study using linked primary care records
}

- Additional supplemental material is published online only. To view, please visit the journal online (http://dx.doi. org/10.1136/bmjqs-2021013425).

${ }^{1}$ University of Exeter Medical School, College of Medicine and Health, University of Exeter, Exeter, UK

${ }^{2}$ Epidemiology of Cancer Healthcare and Outcomes Group, Department of Behavioral Science and Health, Institute of Epidemiology and Health Care, University College London, London, UK

\section{Correspondence to} Dr Bianca Wiering, University of Exeter Medical School, College of Medicine and Health, University of Exeter, Exeter, UK; b.wiering@exeter.ac.uk

Received 29 March 2021 Accepted 2 September 2021

\section{Check for updates}

(C) Author(s) (or their employer(s)) 2021. Re-use permitted under CC BY. Published by BMJ.

To cite: Wiering $B$, Lyratzopoulos G, Hamilton W, et al. BMJ Qual Saf Epub ahead of print: [please include Day Month Year].

doi:10.1136/

bmjqs-2021-013425

\section{Bianca Wiering (D) ,' Georgios Lyratzopoulos (D) ,' Willie Hamilton (D) ,' John Campbell (D) ,' Gary Abel (D) ${ }^{1}$}

\begin{abstract}
Background Clinical guidelines advise GPs in England which patients warrant an urgent referral for suspected cancer. This study assessed how often GPs follow the guidelines, whether certain patients are less likely to be referred, and how many patients were diagnosed with cancer within 1 year of non-referral.
\end{abstract}

Methods We used linked primary care (Clinical Practice Research Datalink), secondary care (Hospital Episode Statistics) and cancer registration data. Patients presenting with haematuria, breast lump, dysphagia, iron-deficiency anaemia, post-menopausal or rectal bleeding for the first time during 2014-2015 were included (for ages where guidelines recommend urgent referral). Logistic regression was used to investigate whether receiving a referral was associated with feature type and patient characteristics. Cancer incidence (based on recorded diagnoses in cancer registry data within 1 year of presentation) was compared between those receiving and those not receiving referrals.

Results 48715 patients were included, of which $40 \%$ $(n=19670)$ received an urgent referral within 14 days of presentation, varying by feature from $17 \%$ (dysphagia) to $68 \%$ (breast lump). Young patients ( $18-24$ vs $55-64$ years; adjusted OR $0.20,95 \% \mathrm{Cl} 0.10$ to $0.42, \mathrm{p}<0.001$ ) and those with comorbidities (4 vs 0 comorbidities; adjusted OR $0.87,95 \% \mathrm{Cl} 0.80$ to $0.94, \mathrm{p}<0.001$ ) were less likely to receive a referral. Associations between patient characteristics and referrals differed across features: among patients presenting with anaemia, breast lump or haematuria, those with multi-morbidity, and additionally for breast lump, more deprived patients were less likely to receive a referral. Of 29045 patients not receiving a referral, 3.6\% (1047) were diagnosed with cancer within 1 year, ranging from $2.8 \%$ for rectal bleeding to $9.5 \%$ for anaemia.

Conclusions Guideline recommendations for action are not followed for the majority of patients presenting with common possible cancer features. A significant number of these patients developed cancer within 1 year of their consultation, indicating scope for improvement in the diagnostic process.

\section{INTRODUCTION}

In 2015, the US Institute of Medicine report 'Improving Diagnosis in Health Care' highlighted the need to improve the quality and safety of diagnosis. ${ }^{1}$ It noted that 'there are few clinical practice guidelines available for diagnosis', contrasting this situation with the large number of guidelines aimed at improving the management of patients with a diagnosed illness. Guidelines for the management of patients with symptoms of possible cancer, which have been introduced in some health systems such as the English National Health Service (NHS), represent an important exception warranting investigation. ${ }^{2-4}$

The period between the patient's first symptomatic presentation and cancer diagnosis is important, as shorter diagnostic intervals may contribute to an earlier stage at diagnosis and better patient experience. ${ }^{5-8}$ In order to improve the quality of diagnostic care and reduce delay, guidelines introduced in England in 2000 recommend that patients who present with certain features of possible cancer should be referred to hospital services by their GP for specialist assessment within 2 weeks. Relevant 'redflag' features for which urgent referrals are recommended were defined by the National Institute for Health and Care Excellence (NICE) initially in $2005^{3} 4$ and updated in 2015 mainly in order to lower the cancer risk threshold for inclusion of features to $3 \% .{ }^{9}$ The guidelines 
include presenting features, which cover clinical signs such as breast lump, test results such as iron-deficiency anaemia, and symptoms such as haematuria.

Guidelines can only ever be as effective as the degree to which they are implemented. The implementation of the Two Week Wait guidelines has been associated with a continuous increase in the number of patients (with or without cancer) who are investigated expeditiously, and in improvements in care outcomes in patients with cancer. ${ }^{10-14}$ While this evidence indicates that the Two Week Wait guidelines are helping to improve diagnostic processes and outcomes in England, the extent to which they are adhered to is unknown. Other evidence suggests that there is some variation in the quality of diagnostic care in cancer patients initially presenting to primary care, ${ }^{15-18}$ the use of endoscopic investigations between GP practices, and the proportion of cancer patients who were diagnosed after a Two Week Wait referral. ${ }^{16-21}$ Furthermore, previous observed inequalities in stage at diagnosis, referral interval and survival ${ }^{22-27}$ may suggest an association between certain patient characteristics (such as age, gender, socioeconomic status and ethnicity) and the risk of guideline non-adherence.

In principle, guideline-discordant referral behaviour may reflect accurate clinical judgement resulting in no adverse clinical outcomes for patients. How often this may be the case is, however, unknown, as studies thus far typically examined selected patients, such as from case series of malpractice claims including patients known to have been harmed. ${ }^{28-30}$ There is little evidence about the outcomes of non-adherence in population-based data. In this paper we focus on concordance with referral guidelines for patients presenting with features of possible cancer. Our research questions are:

1. To what extent are feature-based recommendations about referrals for suspected cancer included in NICE guidelines not followed?

2. Are patient factors associated with guideline discordant/ concordant care regarding referral decisions for suspected cancer?

3. What is the proportion of patients who were diagnosed with cancer within 1 year after guideline discordant non-referral?

\section{METHODS}

\section{Data source}

The Clinical Practice Research Datalink (CPRD) is a large database of routinely collected UK primary care health records. In this study, we used CPRD GOLD data which covered approximately $7 \%$ of the UK population in $2014^{31}$ and is collected from general practices using the Vision clinical software system. It contains clinical and administrative primary care data including diagnoses, investigations and treatments. A subset of CPRD GOLD practices subscribe to allow linkage of data to other sources. The CPRD data were linked at patient level to outpatient Hospital Episode Statistics (HES) data providing information on all referrals to NHS hospitals or NHS funded treatment centres, plus National Cancer Registration and Analysis Service (NCRAS) data providing information on cancer diagnoses, and patients' Index of Multiple Deprivation (IMD — an area based measure of socioeconomic status based on the postcode of a patient's residence). ${ }^{32}$ CPRD linked data have been used extensively for cancer diagnostic studies. ${ }^{33-39}$ HES $^{40}$ and NCRAS $^{41-43}$ quality have been validated and CPRD maintain exacting standards regarding data quality and validation. $^{44} 45$

\section{Study population}

We studied patients presenting to primary care during 2014 and 2015 who presented with one of six features, as recorded in primary care notes: dysphagia, postmenopausal bleeding, iron-deficiency anaemia, rectal bleeding, haematuria, and female breast lump. For these presenting features NICE guidelines recommend urgent (i.e. Two Week Wait) referral for suspected cancer. Inclusion and exclusion criteria are shown in table 1. Age restrictions reflect those patients covered by the guidelines.

\section{Patient and public involvement}

A patient and public involvement group comprising five members met two times throughout the study period. The group was asked to reflect on the study design and research questions. Results, their meaning, and potential explanations were discussed at several stages. They contributed to identifying explanations for GP referral decision making and differences in referral level between patient groups.

\section{Data analysis}

The index consultation was defined for each patient as the first consultation with one of the six features. For these patients, referrals were identified in the HES dataset. Referral in HES is linked to the date the referral was received by the hospital, and recorded as 'Routine', 'Urgent', 'Two Week Wait' or 'Unknown'. As the NICE guidelines define an urgent referral as a referral to see a specialist within 2 weeks, an outcome of urgent referral was defined as a referral having been made in the 14 days after the index consultation with a recorded urgency of 'Urgent' or 'Two Week Wait'. The choice for this definition was pragmatic, acknowledging that there may be administrative delays between a consultation occurring and a referral being made, and was supported by our data showing that most patients referred for an urgent assessment were referred within 2 weeks of the index consultation (online supplemental appendix A, figure A1). Existing feature code lists were used to identify presentations with features of interest. These code lists were developed using robust methods ${ }^{46}$ and have 
Table 1 Patient inclusion and exclusion criteria

\begin{tabular}{ll}
\hline Patient inclusion criteria & $\begin{array}{l}\text { Patient exclusion } \\
\text { criteria }\end{array}$ \\
\hline Registered at a CPRD GOLD & Patients who consulted \\
practice that subscribes to data & with the same feature \\
linkage & of interest as the index \\
& consultation in the \\
& year before the index \\
& consultation
\end{tabular}

A consultation with a medical

code or test result (in the case

of iron-deficiency anaemia)

corresponding to a feature of

interest during 2014 or $2015^{\star}$

$\begin{array}{ll}\begin{array}{ll}\text { Minimum age of patient at } \\ \text { presentation }\end{array} & \text { Dysphagia }-18 \\ & \text { Post-menopausal } \\ & \text { bleeding }-45 \dagger \\ & \text { Iron-deficiency } \\ & \text { anaemia }-60 \\ & \text { Rectal bleeding }-50 \\ & \text { Haematuria }-45 \\ & \text { Breast lump }-30\end{array}$

Continuous registration at the

same general practice from a year

before to a year after their first

index consultation. $\neq$

This table was created by the authors.

*There were minor changes in the recommendations for patients presenting with irondeficiency anaemia and haematuria between the original (2005) and updated (2015) guidance. Therefore, we have restricted analysis to patients where an urgent referral would have been recommended in both sets of guidelines. Specifically for anaemia, inclusion as a first presentation was based on the more stringent test values included in the 2005 NICE guidelines of a haemoglobin level $\leq 11 \mathrm{~g} / \mathrm{dL}$ for men and $\leq 10 \mathrm{~g} /$ $\mathrm{dL}$ for women, plus a ferritin level $<20 \mathrm{ng} / \mathrm{mL}$ and/or a mean red cell volume $<80$ $\mathrm{fL}$, and age restriction of 60 years and over related to the 2015 NICE guidelines. For haematuria, the 2015 NICE guidelines advise referral only if there is no evidence of a urinary tract infection, or if haematuria recurs or persists after successful treatment of a urinary tract infection. As such, the first and/or second consultation where antibiotics were prescribed in the absence of referral were excluded. Third visits within 6 months of the first visit were included regardless of GP treatment and referral decision-making. tAlthough the guidelines do not specify an age range for post-menopausal bleeding, we exclude patients under the age of 45 years due to the small number in our sample $(n=30)$.

¥With the exception of patients who presented with haematuria, the index consultation was defined for each patient as the first consultation with one or more of the six features based on medical codes for five features, and test results for irondeficiency anaemia. For some patients presenting with haematuria, the second or third visit was included as their index consultation instead of the first visit, but exclusion criteria were applied to their first visit.

CPRD, Clinical Practice Research Datalink; GP, general practitioner; NICE, National Institute for Health and Care Excellence.

been used successfully in previous studies. ${ }^{38} 47$ Patient age, gender, comorbidities, and previous cancer diagnosis were extracted from CPRD. Age was treated as a categorical variable with an 18- to 24-year-old group, 10 year age groups between 25 and 84, and an 85 and older group. Comorbidities were conditions included in the Quality of Outcome Framework 2015/2016, using existing code lists applied to all CPRD data before a patient's index consultation. A simple count of comorbidities was used, grouping those with four or more comorbidities together. National quintiles were used to define IMD groups.

After describing the proportion of patients receiving an urgent referral, we investigated which patient groups were more or less likely to receive an urgent referral using multilevel logistic regression. An initial main effects-only model included patient age, gender, deprivation level, number of comorbidities, feature type, previous history of cancer, and a random intercept for referring clinician and general practice to account for clustering of patients within referring clinicians within practices. Between clinician and practice variation is quantified using the odds ratio covering the $95 \%$ mid-range of practices calculated from the estimated random effect variances. ${ }^{48}$ Reference categories were based on the highest number of patients with all genders and features represented. Interaction terms between patient characteristics and feature type were investigated individually with all significant interactions retained in the final model. We excluded 18 cases due to missing data on deprivation level. Significance of categorical variables was tested with a joint Wald test. The study power calculation assumed at least 8000 patients presenting with each feature, which would provide $90 \%$ power $(\mathrm{p}=0.05)$ to see a $4 \%$ absolute change from $25 \%$ discordant care in groups comprising $20 \%$ of the sample for any one feature (for example, 29\% discordant care in the most deprived fifth of patients compared with $25 \%$ in others).

Finally, we investigated how many patients were diagnosed with cancer within 1 year of their index consultation by whether they received an urgent referral or not. Cancer incidence was based on the presence of a tumour in the NCRAS data with an International Classification of Diseases, 10th revision (ICD-10) invasive neoplasm code (C00 to C97 but excluding non-melanoma skin cancer, $\mathrm{C} 44$ ) and a date of diagnosis within 1 year of the index consultation.

\section{Sensitivity analyses}

We performed five sensitivity analyses. First, we repeated the analysis excluding urgent referrals and solely focusing on Two Week Wait ones, to assess whether including urgent referrals had an impact on the findings. Second, we examined the impact of our restriction that referrals must occur within 2 weeks of the index consultation by expanding this window to 90 days. Third, the main analysis was repeated after also adjusting for ethnicity (extracted from HES; coded as white, black, Asian, mixed, and other ethnicity), which was not included in our main analysis due to a considerable amount of missing data (38\%). Fourth, in addition to referrals captured in HES we also considered referrals recorded in CPRD. Where a record of a referral flagged as 'Two Week Wait', 'Red flag' or 'Urgent' in either CPRD or HES was made within 2 weeks of first presentation, the patient was considered to have had an urgent referral. This sensitivity analysis allows for the possibility that GPs made referrals which were not recorded in HES (either because changes were made to the referral after it was made or because the referral was not captured by HES, for example, for an investigation outside of the outpatient setting). Fifth, a 
Table 2 Patient characteristics per feature

\begin{tabular}{|c|c|c|c|c|c|c|c|}
\hline & $\begin{array}{l}\text { Anaemia } \\
(n=1268)\end{array}$ & $\begin{array}{l}\text { Rectal bleeding } \\
(n=13067)\end{array}$ & $\begin{array}{l}\text { Dysphagia } \\
(\mathrm{n}=8197)\end{array}$ & $\begin{array}{l}\text { Breast lump } \\
(n=16118)\end{array}$ & $\begin{array}{l}\text { Haematuria } \\
(\mathrm{n}=6529)\end{array}$ & $\begin{array}{l}\text { Post-menopausal } \\
\text { bleeding } \\
\text { ( } \mathrm{n}=3536)\end{array}$ & \\
\hline & $\mathrm{N}(\%)$ & $\mathrm{N}(\%)$ & $\mathrm{N}(\%)$ & $\mathrm{N}(\%)$ & $\mathrm{N}(\%)$ & $\mathrm{N}(\%)$ & Total $(n=48715)$ \\
\hline \multicolumn{8}{|l|}{ Age } \\
\hline 18 to 24 years & - & - & $191(2.3 \%)$ & - & - & - & $191(0.4 \%)$ \\
\hline 25 to 34 years & - & - & $404(4.9 \%)$ & $1825(11.3 \%)$ & - & - & $2229(4.6 \%)$ \\
\hline 35 to 44 years & - & - & $733(8.9 \%)$ & $4798(29.8 \%)$ & - & - & $5531(11.4 \%)$ \\
\hline 45 to 54 years & - & $2355(18.0 \%)$ & $1308(16.0 \%)$ & $5072(31.5 \%)$ & $1107(17.0 \%)$ & $1010(28.6 \%)$ & $10852(22.3 \%)$ \\
\hline 55 to 64 years & $103(8.1 \%)$ & $3815(29.2 \%)$ & $1521(18.6 \%)$ & $1883(11.7 \%)$ & $1305(20.0 \%)$ & $1463(41.4 \%)$ & $10090(20.7 \%)$ \\
\hline 65 to 74 years & $350(27.6 \%)$ & $3509(26.9 \%)$ & $1660(20.3 \%)$ & $1432(8.9 \%)$ & $1826(28.0 \%)$ & $658(18.6 \%)$ & $9435(19.4 \%)$ \\
\hline 75 to 84 years & $481(37.9 \%)$ & $2468(18.9 \%)$ & $1513(18.5 \%)$ & $791(4.9 \%)$ & $1629(25.0 \%)$ & $313(8.9 \%)$ & $7195(14.8 \%)$ \\
\hline 85 or older & $334(26.3 \%)$ & $920(7.0 \%)$ & $867(10.6 \%)$ & $317(2.0 \%)$ & $662(10.1 \%)$ & $92(2.6 \%)$ & $3192(6.6 \%)$ \\
\hline Gender (female) & 709 (55.9\%) & $6547(50.1 \%)$ & $4519(55.1 \%)$ & $16118(100 \%)$ & $2223(34.1 \%)$ & $3536(100 \%)$ & 33652 (69.1\%) \\
\hline \multicolumn{8}{|l|}{ IMD } \\
\hline 1 (least deprived) & $249(19.6)$ & $3475(26.6 \%)$ & $1864(22.7 \%)$ & $4368(27.1 \%)$ & $1715(26.3 \%)$ & $1001(28.3 \%)$ & $12672(26.0 \%)$ \\
\hline 2 & $276(21.8 \%)$ & $2996(22.9 \%)$ & $1727(21.1 \%)$ & $3491(21.7 \%)$ & $1548(23.7 \%)$ & $795(22.5 \%)$ & $10833(22.2 \%)$ \\
\hline 3 & $277(21.9 \%)$ & $2733(20.9 \%)$ & $1786(21.8 \%)$ & $3284(20.4 \%)$ & $1390(21.3 \%)$ & $718(20.3 \%)$ & 10188 (20.9\%) \\
\hline 4 & $272(21.5 \%)$ & $2193(16.8 \%)$ & $1524(18.6 \%)$ & $2737(17.0 \%)$ & $1086(16.6 \%)$ & $529(15.0 \%)$ & $8341(17.1 \%)$ \\
\hline 5 (most deprived) & $192(15.1 \%)$ & $1664(12.7 \%)$ & $1294(15.8 \%)$ & $2232(13.9 \%)$ & $789(12.1 \%)$ & $492(13.9 \%)$ & $6663(13.7 \%)$ \\
\hline \multicolumn{8}{|l|}{ Ethnicity } \\
\hline White & 796 (62.8\%) & $6392(48.9 \%)$ & $3980(48.6 \%)$ & $10535(65.4 \%)$ & $4130(63.3 \%)$ & $2249(63.6 \%)$ & $28082(57.7 \%)$ \\
\hline Black & $13(1.0 \%)$ & $116(0.9 \%)$ & $54(0.7 \%)$ & $254(1.6 \%)$ & $58(0.9 \%)$ & $61(1.7 \%)$ & $556(1.1 \%)$ \\
\hline Asian & $31(2.4 \%)$ & $222(1.7 \%)$ & $182(2.2 \%)$ & $364(2.3 \%)$ & $93(1.4 \%)$ & $95(2.7 \%)$ & $987(2.0 \%)$ \\
\hline Mixed & $3(0.2 \%)$ & $28(0.2 \%)$ & $24(0.3 \%)$ & $112(0.7 \%)$ & $14(0.2 \%)$ & $12(0.3 \%)$ & $193(0.4 \%)$ \\
\hline Other & $12(1.0 \%)$ & $78(0.6 \%)$ & $58(0.7 \%)$ & $184(1.1 \%)$ & $38(0.6 \%)$ & $43(1.2 \%)$ & $413(0.9 \%)$ \\
\hline \multicolumn{8}{|l|}{ Comorbidities } \\
\hline 0 & $76(6.0 \%)$ & $2164(16.6 \%)$ & $1355(16.5 \%)$ & $4668(29.0 \%)$ & $927(14.2 \%)$ & $588(16.6 \%)$ & $9778(20.1 \%)$ \\
\hline 1 & $175(13.8 \%)$ & $2991(22.9 \%)$ & $1690(20.6 \%)$ & $4174(25.9 \%)$ & $1332(20.4 \%)$ & $923(26.1 \%)$ & $11285(23.2 \%)$ \\
\hline 2 & $258(20.4 \%)$ & $2965(22.7 \%)$ & $1765(21.5 \%)$ & $3598(22.3 \%)$ & $1479(22.7 \%)$ & $808(22.9 \%)$ & $10873(22.3 \%)$ \\
\hline 3 & 265 (20.9\%) & $2220(17.0 \%)$ & $1364(16.6 \%)$ & $2170(13.5 \%)$ & $1249(19.1 \%)$ & $629(17.8 \%)$ & $7897(16.2 \%)$ \\
\hline$\geq 4$ & 494 (39.0\%) & $2727(20.9 \%)$ & $2023(24.7 \%)$ & $1508(9.4 \%)$ & $1542(23.6 \%)$ & $588(16.6 \%)$ & $8882(18.2 \%)$ \\
\hline
\end{tabular}

This table was created by the authors.

IMD, Index of Multiple Deprivation.

sensitivity analysis was performed including neoplasm in situ (ICD-10 codes D00 to D48) in addition to invasive neoplasms. All analyses were conducted using the statistical software Stata v14.2. ${ }^{49}$

\section{RESULTS}

\section{Patient characteristics}

There were 48715 index consultations by patients with a feature of interest where a Two Week Wait referral would have been recommended (table 2). Among these patients, the most common presenting features were breast lump (33\%) and rectal bleeding $(27 \%)$. The mean age of the included patients was 60.4 years (range 18-104; SD 15.6). However, age ranges varied by feature, with the lowest mean age of 49.5 years (range 30-104 years; SD 13.7) for patients with breast lump and the highest mean age of 77.9 years for patients with anaemia (range 60-102; SD 9.1). Most patients had at least one comorbidity (80\%). Patients who lived in an area classed as the lowest quintile (least deprived) of the IMD were over-represented $(26 \%$ vs an expected 20\%).

\section{Urgent referrals}

Overall, 40\% ( $n=19670)$ of patients received an urgent referral within 2 weeks of visiting the GP. The percentage of urgent referrals varied greatly by presenting feature, ranging from 17\% $(\mathrm{n}=1384)$ for patients with dysphagia to 68\% $(n=11007)$ for patients with breast lump (table 3).

\section{Associations between patient characteristics and urgent referrals}

The main effects-only models showed evidence that age $(\mathrm{p}<0.001)$, feature type $(\mathrm{p}<0.001)$, and comorbidities $(\mathrm{p}<0.001)$ were associated with the probability of receiving an urgent referral (online supplemental appendix A, figure A2; table 4). Patients with breast lump were most likely to receive a referral (adjusted OR compared with rectal bleeding: 16.85, 95\% CI 15.56 to 18.26). Younger age (adjusted OR 18-24 years vs 55-64 years: $0.20,95 \% \mathrm{CI} 0.10$ to 0.42 ) and greater number of comorbidities (adjusted OR 4 comorbidities vs 0 comorbidities: $0.87,95 \% \mathrm{CI} 0.80$ to 0.94 ) were associated with a lower chance of receiving an urgent 
Table 3 Type of referrals given to patients within 2 weeks after visiting the GP with one or more of the six features

\begin{tabular}{|c|c|c|c|c|}
\hline \multirow[b]{3}{*}{ Features } & \multirow[b]{2}{*}{$\begin{array}{l}\text { Number of patients who did not } \\
\text { receive an urgent referral }\end{array}$} & \multirow[b]{2}{*}{$\begin{array}{l}\text { Number of patients who did } \\
\text { receive an urgent referral }\end{array}$} & Referral types* & \multirow[b]{2}{*}{ Urgent referrals } \\
\hline & & & $\begin{array}{l}\text { Two Week Wait } \\
\text { referrals }\end{array}$ & \\
\hline & $\mathrm{N}(\%)$ & $\mathrm{N}(\%)$ & $\mathrm{N}(\%)^{*}$ & $\mathrm{~N}(\%)^{*}$ \\
\hline Anaemia $(n=1268)$ & $1007(79.4 \%)$ & $261(20.6 \%)$ & $176(13.9 \%)$ & $85(6.7 \%)$ \\
\hline Rectal bleeding ( $n=13067)$ & $10752(82.3 \%)$ & $2315(17.7 \%)$ & $1427(10.9 \%)$ & $888(6.8 \%)$ \\
\hline Dysphagia $(n=8197)$ & $6813(83.1 \%)$ & $1384(16.9 \%)$ & $990(12.1 \%)$ & $394(4.8 \%)$ \\
\hline Breast lump ( $n=16118$ ) & $5111(31.7 \%)$ & 11007 (68.3\%) & 8052 (50.0\%) & $2955(18.3 \%)$ \\
\hline Haematuria $+(n=6529)$ & $4043(61.9 \%)$ & $2486(38.1 \%)$ & $1479(22.7 \%)$ & $1007(15.4 \%)$ \\
\hline Post-menopausal bleeding ( $n=3536)$ & $1319(37.3 \%)$ & $2217(62.7 \%)$ & $1598(45.2 \%)$ & $619(17.5 \%)$ \\
\hline Total $(n=48715)$ & $29045(59.6 \%)$ & 19670 (40.4\%) & $13722(28.2 \%)$ & $5948(12.2 \%)$ \\
\hline
\end{tabular}

This table was created by the authors.

*Patients may have received several referral types within 2 weeks. The table describes whether patients received a Two Week Wait referral, and if not, whether they received an urgent referral.

†For haematuria, the number of referrals is based on referrals within 2 weeks after the first visit, referrals within 2 weeks after the second visit if patients received urinary tract infection treatment the first time, and referrals within 2 weeks after the third visit if patients received treatment during their first and second visit.

GP, general practitioner.

referral (online supplemental appendix A, figure A2; table 4). There was substantial variation between both clinicians and practices, with the modelled OR covering the middle $95 \%$ of clinicians being 2.62 , and practice being 1.62. The final model, including interactions between feature and patient factors, indicated that the association between patient characteristics and urgent referrals was highly dependent on the

Table 4 Associations between patient characteristics and urgent referrals received within 2 weeks after visiting the GP (main analysis)

\begin{tabular}{|c|c|c|c|c|c|c|c|c|}
\hline & Unadjusted OR & Lower $95 \% \mathrm{Cl}$ & Upper $95 \% \mathrm{Cl}$ & $P$ value & OR & Lower $95 \% \mathrm{Cl}$ & Upper $95 \% \mathrm{Cl}$ & $P$ value \\
\hline \multicolumn{9}{|l|}{ Features } \\
\hline Anaemia & 1.17 & 1.01 & 1.37 & $<0.001$ & 1.14 & 0.97 & 1.33 & $<0.001$ \\
\hline Rectal bleeding & Ref & Ref & Ref & & Ref & Ref & Ref & \\
\hline Dysphagia & 0.91 & 0.84 & 0.99 & & 1.01 & 0.93 & 1.09 & \\
\hline Breast lump & 12.15 & 11.41 & 12.94 & & 16.85 & 15.56 & 18.26 & \\
\hline Haematuria & 3.29 & 3.05 & 3.54 & & 3.29 & 3.05 & 3.54 & \\
\hline Post-menopausal bleeding & 9.57 & 8.74 & 10.48 & & 9.93 & 9.01 & 10.94 & \\
\hline \multicolumn{9}{|l|}{ Age } \\
\hline 18 to 24 years & 0.08 & 0.04 & 0.16 & $<0.001$ & 0.20 & 0.10 & 0.42 & $<0.001$ \\
\hline 25 to 34 years & 1.41 & 1.28 & 1.56 & & 0.37 & 0.33 & 0.41 & \\
\hline 35 to 44 years & 2.25 & 2.10 & 2.42 & & 0.58 & 0.53 & 0.64 & \\
\hline 45 to 54 years & 1.47 & 1.39 & 1.56 & & 0.80 & 0.75 & 0.86 & \\
\hline 55 to 64 years & Ref & Ref & Ref & & Ref & Ref & Ref & \\
\hline 65 to 74 years & 0.90 & 0.84 & 0.96 & & 1.11 & 1.04 & 1.20 & \\
\hline 75 to 84 years & 0.83 & 0.78 & 0.89 & & 1.20 & 1.11 & 1.30 & \\
\hline 85 or older & 0.64 & 0.58 & 0.71 & & 0.96 & 0.86 & 1.07 & \\
\hline Sex (female) & 3.06 & 2.92 & 3.21 & $<0.001$ & 1.03 & 0.97 & 1.10 & 0.365 \\
\hline \multicolumn{9}{|l|}{ IMD } \\
\hline 1 (least deprived) & Ref & Ref & Ref & 0.775 & Ref & Ref & Ref & 0.246 \\
\hline 2 & 0.98 & 0.93 & 1.05 & & 1.01 & 0.94 & 1.09 & \\
\hline 3 & 1.03 & 0.96 & 1.10 & & 1.05 & 0.98 & 1.13 & \\
\hline 4 & 1.00 & 0.93 & 1.08 & & 1.09 & 1.01 & 1.18 & \\
\hline 5 (most deprived) & 1.00 & 0.92 & 1.08 & & 1.06 & 0.97 & 1.17 & \\
\hline \multicolumn{9}{|l|}{ Comorbidities } \\
\hline 0 & Ref & Ref & Ref & $<0.001$ & Ref & Ref & Ref & $<0.001$ \\
\hline 1 & 0.90 & 0.85 & 0.95 & & 0.99 & 0.92 & 1.06 & \\
\hline 2 & 0.85 & 0.80 & 0.90 & & 0.97 & 0.91 & 1.04 & \\
\hline 3 & 0.74 & 0.69 & 0.79 & & 0.89 & 0.82 & 0.96 & \\
\hline$\geq 4$ & 0.60 & 0.56 & 0.64 & & 0.87 & 0.80 & 0.94 & \\
\hline Previous history of cancer & - & - & - & & 0.90 & 0.82 & 0.99 & 0.035 \\
\hline
\end{tabular}

This table was created by the authors.

$\mathrm{GP}$, general practitioner; IMD, Index of Multiple Deprivation. 
patient's presenting features. Although there was no evidence for an average effect of deprivation across all features, there was evidence that patients living in more deprived neighbourhoods were more likely to be referred urgently if they presented with haematuria, post-menopausal bleeding, or rectal bleeding, though the opposite was true for women presenting with breast lump (online supplemental appendix A, figure A3(a)). Furthermore, patients presenting with anaemia, breast lump or haematuria were less likely to receive an urgent referral if they had a higher number of comorbidities, though the gradient was stronger in patients with anaemia than for other features (online supplemental appendix A, figure A3(b)). Finally, although the association between age and urgent referral was similar for all patients, the size of age variation was greater for patients presenting with dysphagia and breast lump (online supplemental appendix A, figure A3(c)). However, this largely reflected the larger age range covered by referral guidelines for those features. Sensitivity analyses excluding the $58 \%$ of patients who received an urgent as opposed to Two Week Wait referral (online supplemental appendix A, table A1), or including ethnicity (online supplemental appendix A, table A2), showed similar results. The sensitivity analysis for urgent referrals occurring within 90 days of presentation showed that 44\% (as opposed to $40 \%$ in the main analysis) of patients received a referral, and showed similar variation by age, feature type and number of comorbidities to the main analysis (online supplemental appendix A, table A3). Finally, the sensitivity analysis including urgent referrals recorded in either HES or CPRD within 2 weeks of the index consultation identified a further 3503 patients receiving a referral, indicating that $48 \%$ of patients received an urgent referral (online supplemental appendix A, table A4).

\section{Cancer diagnoses}

Of the 19670 patients who received an urgent referral, 1950 (9.9\%) went on to be diagnosed with cancer within 1 year. Of the 29045 patients who did not receive an urgent referral, 1047 (3.6\%) patients were diagnosed with cancer within 1 year. As a result, 35\% of all patients diagnosed with cancer in the year after consulting their GP with one of the six features had not received a recorded urgent referral within 2 weeks of their index consultation (online supplemental appendix A, table A5). The percentage of patients diagnosed with cancer without having received a referral varied between features, from $2.8 \%$ for rectal bleeding to $9.5 \%$ for patients with iron-deficiency anaemia (table 5; Online supplemental appendix A, figure A4). The sensitivity analysis, which included urgent referrals captured by either CPRD or HES, found that $3.2 \%$ of patients who did not receive a referral were diagnosed with cancer within 1 year of their index consultation (online supplemental appendix A, table
A6). The sensitivity analysis, including both invasive neoplasms and neoplasms in situ, showed similar results with $4.2 \%$ of patients diagnosed with either type of neoplasm within 1 year (compared with $3.6 \%$ for invasive neoplasms and HES recorded referrals alone) (online supplemental appendix A, table A7). The percentage of patients diagnosed with cancer of a specific site within 1 year of not receiving an urgent referral was low for most cancers (table 5), with the exceptions of colorectal cancer for patients with irondeficiency anaemia (5.5\%), breast cancer for patients with breast lump (3.5\%), and uterine cancer for patients with post-menopausal bleeding (2.9\%).

\section{DISCUSSION}

\section{Statement of principal findings}

Six out of 10 patients presenting to primary care with a high-risk feature of possible cancer did not receive an urgent referral in the 14 days after presentation, despite this being a guideline-recommended action. Urgent referral frequency varied by feature, with patients with breast lump receiving the highest percentage of referrals and patients with dysphagia the lowest. Younger patients, and those with comorbidities were less likely to receive an urgent referral. Associations between patient characteristics and urgent referrals differed by feature. More deprived women with breast lump, and patients with anaemia, breast lump, or haematuria and multi-morbidity were less likely to receive a referral; $3.6 \%$ of patients who did not receive an urgent referral were diagnosed with cancer within 1 year, this percentage varying between $2.8 \%$ for rectal bleeding and $9.5 \%$ for iron-deficiency anaemia.

\section{Strengths and limitations}

We used a large, longitudinal, validated linked dataset which has been used extensively for cancer diagnostic studies, ${ }^{10} 5051$ enabling important insights into patients' journeys through the healthcare system. However, there are limitations. First, as an urgently referred patient would usually be investigated in an outpatient setting, the HES dataset comprised outpatient hospital data. Consequently, patients referred and admitted to hospital or directed to an emergency department will not have been identified even though timely action was taken. However, the number of such patients is likely small for the studied presenting features, especially given the substantial decrease in the number of cancers diagnosed following emergency GP referrals in the last decade. ${ }^{13}$ Second, identification of index consultations with one of the six features was based on medical codes in patient records. Some patients may have been missed because the feature was only recorded in inaccessible 'free text' (which is not available to researchers to avoid de-anonymisation) or because the feature was not recorded at all. However, CPRD studies of free-text data suggest it usually only confirms coded entries. ${ }^{52}$ Consequently, some patients 
Table 5 Main cancer diagnoses within 1 year of the index GP visit

Main cancer types for patients who did not receive

Main cancer types for patients who did receive an an urgent referral

urgent referral

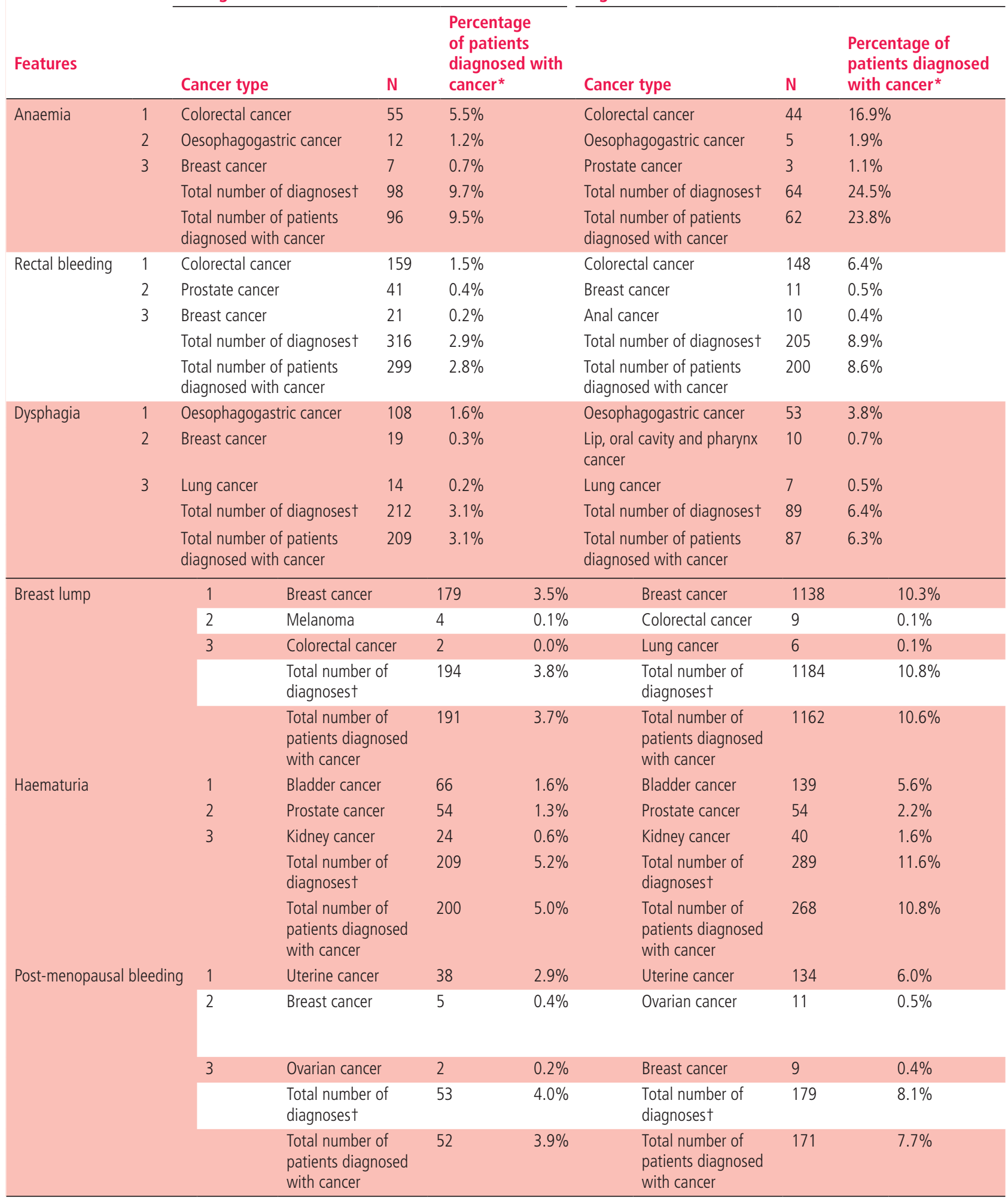

This table was created by the authors.

* Percentage of cancer diagnoses compared with the number of patients who received or did not receive an urgent referral. tSome patients received more than one separate cancer diagnosis within 1 year of their GP visit with a feature of interest.

$\mathrm{GP}$, general practitioner. 
with features of interest may not have been included in the study. However, those who were included almost certainly had the feature, and thus a Two Week Wait referral would have been recommended. Third, inclusion of patients was limited to 2014 and 2015 as cancer registry data were only available up to and including 2016 at the time of data extraction. However, it is unlikely that this will have affected results, as the guidelines had been in use for a number of years, and analyses were restricted to patients where an urgent referral would have been recommended in both the 2005 and 2015 guidance. Fourth, we excluded patients with haematuria who were treated for possible urinary tract infection (unless it was not the last visit or a third consultation within 6 months) on the basis of prescriptions for two of the most common first-line antibiotics for urinary tract infection. A small number of patients will have been prescribed different antibiotics and been included in error. Fifth, although the study showed that many patients were diagnosed with cancer after not receiving an urgent referral after presenting with a suspected cancer feature, we were unable to give insight into the potential impact of non-referral on cancer stage. Finally, we note that although for three features we exceeded our planned sample size, the number of patients presenting with iron-deficiency anaemia or post-menopausal bleeding was significantly less than planned.

\section{Comparison with existing evidence and meaning of the study}

Previous studies have reported that the number of GP consultations before referral varied by cancer type. ${ }^{53}$ It appears that GPs are less likely to suspect cancer for some features compared with others. This may be partially explained by the greater likelihood of some features being caused by other explanations than cancer. However, the risk of cancer with all these features is always low in absolute terms, with iron-deficiency anaemia having the highest positive predictive value of the six for cancer (for men over 60 years with a haemoglobin $<11 \mathrm{~g} / \mathrm{dL}$ and features of iron deficiency, the positive predictive value is $13 \%{ }^{54}$ ). The decision to refer may be influenced by factors other than guidelines, such as GPs' symptom interpretation, ${ }^{55}$ additional presenting features supporting a different diagnosis, and clinical intuition, ${ }^{56}$ but also by how local health services are organised. ${ }^{20}$ Variation in referral has been shown to be partly attributable to Clinical Commissioning Groups (CCGs) and Acute Hospital Trusts. ${ }^{20}$ This is supported by qualitative research suggesting that GPs are hesitant to refer or even feel pressured by CCGs to not refer due to resource pressures. ${ }^{57}$ Additionally, although probably only responsible for a small proportion of nonreferrals, there are a number of other factors which may affect whether a referral was made or recorded (box 1). Regardless of the GPs' reasons for referral or
Box 1

\section{Mechanisms affecting referral}

Although we expect that it only affects a small number of patients, there are a number of mechanisms besides GP referral decision-making which may potentially influence whether an urgent referral was made or recorded:

- Patients were admitted to hospital via emergency admission

- The referral was not accepted by the hospital. (This should be captured by the sensitivity analysis including Clinical Practice Research Datalink (CPRD) referrals)

- The patient refused to be referred

- A downgrade of the urgency level of the referral was requested by the hospital. (This should still be captured in the CPRD sensitivity analysis)

- Index consultation took place with out-of-hours practice services

- Variations in local guidelines for referral. (For most patients this should be captured in either the sensitivity analysis including CPRD referrals or the sensitivity analysis including referrals made up to 90 days after presentation)

- The patient received a related referral before first presentation, which affected the decision to refer

non-referral, our study shows that GPs often made the right decision regarding referral for their patients. Given the proportion of patients going on to be diagnosed with cancer was considerably higher in those receiving an urgent referral than those who did not, we can conclude that GP referral decision-making is not without value. However, given the number of patients diagnosed with cancer after non-referral, we may question whether clinical judgement is good enough: $5.5 \%$ of patients with anaemia not receiving an urgent referral were diagnosed with colorectal cancer within 1 year, $3.5 \%$ of women presenting with breast lump who did not receive a referral were diagnosed with breast cancer, and $2.9 \%$ who presented with post-menopausal bleeding were diagnosed with uterine cancer. In these patients it can be argued that guideline-discordant decision-making may have resulted in a missed opportunity to diagnose early. Better adherence to the guidelines may therefore be important in order to increase detection rate, even for alarm features with already high urgent referral rates.

Our finding that younger patients were less likely to receive an urgent referral reflects earlier research reporting that younger patients typically experience longer diagnostic timelines. ${ }^{53}$ The present study also offers new insights into how multi-morbidity may affect diagnostic timeliness. Although there are suggestions that more contact with health services can shorten diagnostic intervals, a growing body of evidence suggests that multi-morbidity can also prolong diagnostic intervals. ${ }^{158-61}$ Given our findings, 
it may be these prolonged intervals arise, in part, due to a lower likelihood of receiving an urgent referral. Additionally, research suggests that multi-morbidity is associated with decreased use of specialist investigations. ${ }^{62}$ This may explain the strong multi-morbidity gradient observed for patients with anaemia where urgent referral would lead to an invasive test. Future research investigating how multi-morbidity affects GP referral decision-making for potential cancer features may help target improvement efforts.

Although, on average, deprivation was not associated with urgent referrals, more deprived patients with haematuria, rectal or post-menopausal bleeding were more likely to receive a referral. Although we can only speculate, this finding could be explained by earlier research suggesting that deprived patients are more likely to delay presentation, ${ }^{63} 64$ resulting in more serious potential cancer features, increasing the chance of an urgent referral. On the other hand, more deprived women presenting with breast lump were less likely to receive an urgent referral. As few women with breast cancer delay presentation, ${ }^{63}$ the association between deprivation and referral is likely to reflect differences post-presentation. Patients with a higher socioeconomic status tend to be more effectively able to communicate their symptoms and concerns, ${ }^{65} 66$ while GPs' communication tends to be more patientcentred with less deprived patients. ${ }^{67}$ This may potentially result in closer alignment in perceptions of symptom significance ${ }^{68}$ and influence GPs' decision to refer.

We have identified patient groups who may be at risk of longer diagnostic timelines. GPs may be less likely to refer patients when their age, ${ }^{69}$ or alternative medical explanations, suggest a lower risk of cancer. However, guidelines incorporate patient age and thus recommended action is still appropriate for those age groups.

Clinical practice guidelines have been shown to improve treatment quality for a range of conditions and could also help to improve the quality of the diagnostic process. However, our study shows that recommendations for the assessment of patients with features of possible cancer are not always followed. Stricter adherence to the guidelines and increased awareness of patient groups especially at risk of long diagnostic timelines may help improve early diagnosis and ultimately cancer survival rates. Due to the potential impact of regional health services, interventions to reduce guideline discordant behaviour may have more impact if they do not just focus on GPs and individual practices, but also on local diagnostic service provision.

Acknowledgements This work was funded by Cancer Research UK (C50627/A25622). This research is also linked to the CanTest Collaborative, which is funded by Cancer Research UK (C8640/A23385), of which WH is the Co-Director, GL is the Associate Director and GA is Senior Faculty. GL is supported by a Cancer Research UK Advanced Clinician Scientist Fellowship Award (C18081/A18180).

Contributors The study was conceived by GA, building on previous work by GL and GA. BW curated the data after receiving input from all authors. BW analysed the data and produced the first draft of the paper with supervision of GA. All authors interpreted findings and identified issues for discussion. The draft was reviewed and modified with input from all authors over a number of versions. All authors saw and approved the final version. GA and BW are guarantors.

Funding This study was funded by Cancer Research UK (C50627/A25622).

Competing interests All authors have completed the ICMJE uniform disclosure form at www.icmje.org/ coi_disclosure. pdf and declare: all authors had financial support from Cancer Research UK for the submitted work; no other financial relationships with any organisations that might have an interest in the submitted work in the previous three years, no other relationships or activities that could appear to have influenced the submitted work.

\section{Patient consent for publication Not required.}

Ethics approval Observational studies using anonymised CPRD data are not required to obtain study-specific ethical approval. The National Research Ethics Service (NRES) has granted ethical approval for all observational research using anonymised CPRD data (please see www.cprd.com for more information). Protocol approval was granted by the CPRD Independent Scientific Advisory Committee (ISAC - Protocol 18 307R) and all data were anonymised and de-identified before it was supplied.

Provenance and peer review Not commissioned; externally peer reviewed.

Data availability statement Data may be obtained from a third party and are not publicly available. Routinely collected patient electronic health data was provided by CPRD. Access to data from CPRD is subject to a licence agreement and protocol approval from the Independent Scientific Advisory Committee (ISAC).

Supplemental material This content has been supplied by the author(s). It has not been vetted by BMJ Publishing Group Limited (BMJ) and may not have been peer-reviewed. Any opinions or recommendations discussed are solely those of the author(s) and are not endorsed by BMJ. BMJ disclaims all liability and responsibility arising from any reliance placed on the content. Where the content includes any translated material, BMJ does not warrant the accuracy and reliability of the translations (including but not limited to local regulations, clinical guidelines, terminology, drug names and drug dosages), and is not responsible for any error and/or omissions arising from translation and adaptation or otherwise.

Open access This is an open access article distributed in accordance with the Creative Commons Attribution 4.0 Unported (CC BY 4.0) license, which permits others to copy, redistribute, remix, transform and build upon this work for any purpose, provided the original work is properly cited, a link to the licence is given, and indication of whether changes were made. See: https://creativecommons.org/licenses/by/4.0/.

\section{ORCID iDs}

Bianca Wiering http://orcid.org/0000-0001-6708-5705 Georgios Lyratzopoulos http://orcid.org/0000-0002-28737421

Willie Hamilton http://orcid.org/0000-0003-1611-1373

John Campbell http://orcid.org/0000-0002-6752-3493

Gary Abel http://orcid.org/0000-0003-2231-5161

\section{REFERENCES}

1 Balogh E, Miller B, Ball J, Board on Health Care Services, Institute of Medicine. The diagnostic process. improving diagnosis in health care national academies of sciences, engineering, and medicine, 2015. 
2 Olesen F, Hansen RP, Vedsted P. Delay in diagnosis: the experience in Denmark. Br J Cancer 2009;101 Suppl 2:S5-8.

3 Mansell G, Shapley M, Jordan JL, et al. Interventions to reduce primary care delay in cancer referral: a systematic review. Br J Gen Pract 2011;61:e821-35.

4 National Institute for Health and Care Excellence. Referral guidelines for suspected cancer (clinical guideline 27). NICE, 2005. www.nice.org.uk/guidance/cg27

5 Hamilton W. Cancer diagnosis in primary care. Br J Gen Pract 2010;60:121-8.

6 Weller D, Vedsted P, Rubin G, et al. The Aarhus statement: improving design and reporting of studies on early cancer diagnosis. Br J Cancer 2012;106:1262-7.

7 Tørring ML, Frydenberg M, Hansen RP, et al. Time to diagnosis and mortality in colorectal cancer: a cohort study in primary care. Br J Cancer 2011;104:934-40.

8 Richards MA, Westcombe AM, Love SB, et al. Influence of delay on survival in patients with breast cancer: a systematic review. Lancet 1999;353:1119-26.

9 National Institute for Health and Care Excellence. Suspected cancer: recognition and referral. NICE, 2015. https://www.nice. org.uk/guidance/ng12

10 Neal RD, Din NU, Hamilton W, et al. Comparison of cancer diagnostic intervals before and after implementation of NICE guidelines: analysis of data from the UK general practice research database. Br J Cancer 2014;110:584-92.

11 Pham TM, Gomez-Cano M, Salika T, et al. Diagnostic route is associated with care satisfaction independently of tumour stage: evidence from linked English cancer patient experience survey and cancer registration data. Cancer Epidemiol 2019;61:70-8.

12 Salika T, Abel GA, Mendonca SC, et al. Associations between diagnostic pathways and care experience in colorectal cancer: evidence from patient-reported data. Frontline Gastroenterol 2018;9:241-8.

13 Herbert A, Abel GA, Winters S. Cancer diagnoses after emergency GP referral or A\&E attendance in England: determinants and time trends in routes to diagnosis data, 2006-2015. Br J Gen Prac 2019;69:e724-30.

14 Round T, Gildea C, Ashworth M, et al. Association between use of urgent suspected cancer referral and mortality and stage at diagnosis: a 5-year national cohort study. Br J Gen Pract 2020;70:e389-98.

15 Swann R, Lyratzopoulos G, Rubin G, et al. The frequency, nature and impact of GP-assessed avoidable delays in a population-based cohort of cancer patients. Cancer Epidemiol 2020;64:101617.

16 Møller H, Gildea C, Meechan D, et al. Use of the English urgent referral pathway for suspected cancer and mortality in patients with cancer: cohort study. BMJ 2015;351:h5102.

17 Meechan D, Gildea C, Hollingworth L, et al. Variation in use of the 2-week referral pathway for suspected cancer: a crosssectional analysis. Br J Gen Pract 2012;62:e590-7.

18 Elliss-Brookes L, McPhail S, Ives A, et al. Routes to diagnosis for cancer - determining the patient journey using multiple routine data sets. Br J Cancer 2012;107:1220-6.

19 Abel G, Saunders CL, Mendonca SC, et al. Variation and statistical reliability of publicly reported primary care diagnostic activity indicators for cancer: a cross-sectional ecological study of routine data. BMJ Qual Saf 2018;27:21-30.

20 Burton C, O'Neill L, Oliver P, et al. Contribution of primary care organisation and specialist care provider to variation in GP referrals for suspected cancer: ecological analysis of national data. BMJ Qual Saf 2020;29: bmjqs-2019-009469:296-303.

21 Lyratzopoulos G, Vedsted P, Singh H. Understanding missed opportunities for more timely diagnosis of cancer in symptomatic patients after presentation. Br J Cancer 2015;112 Suppl 1:S84-91.

22 Lyratzopoulos G, Abel GA, McPhail S, et al. Gender inequalities in the promptness of diagnosis of bladder and renal cancer after symptomatic presentation: evidence from secondary analysis of an English primary care audit survey. BMJ Open 2013;3:e002861.

23 Lyratzopoulos G, Abel GA, Brown CH, et al. Sociodemographic inequalities in stage of cancer diagnosis: evidence from patients with female breast, lung, colon, rectal, prostate, renal, bladder, melanoma, ovarian and endometrial cancer. Ann Oncol 2013;24:843-50.

24 Rutherford MJ, Ironmonger L, Ormiston-Smith N, et al. Estimating the potential survival gains by eliminating socioeconomic and sex inequalities in stage at diagnosis of melanoma. Br J Cancer 2015;112 Suppl 1:S116-23.

25 Rutherford MJ, Abel GA, Greenberg DC, et al. The impact of eliminating age inequalities in stage at diagnosis on breast cancer survival for older women. Br J Cancer 2015;112 Suppl 1:S124-8.

26 Rutherford MJ, Hinchliffe SR, Abel GA, et al. How much of the deprivation gap in cancer survival can be explained by variation in stage at diagnosis: an example from breast cancer in the East of England. Int J Cancer 2013;133:2192-200.

27 Hayes L, Adams J, McCallum I, et al. Age-related and socioeconomic inequalities in timeliness of referral and start of treatment in colorectal cancer: a population-based analysis. $J$ Epidemiol Community Health 2021;75:1-9.

28 Bishop TF, Ryan AM, Ryan AK, et al. Paid malpractice claims for adverse events in inpatient and outpatient settings. JAMA 2011;305:2427-31.

29 Aaronson EL, Quinn GR, Wong CI, et al. Missed diagnosis of cancer in primary care: insights from malpractice claims data. $J$ Healthc Risk Manag 2019;39:19-29.

30 Wallace E, Lowry J, Smith SM, et al. The epidemiology of malpractice claims in primary care: a systematic review. BMJ Open 2013;3. doi:10.1136/bmjopen-2013-002929. [Epub ahead of print: 1807 2013].

31 Herrett E, Gallagher AM, Bhaskaran K, et al. Data resource profile: Clinical Practice Research Datalink (CPRD). Int J Epidemiol 2015;44:827-36. doi:10.1093/ije/dyv098

32 Padmanabhan S, Carty L, Cameron E, et al. Approach to record linkage of primary care data from Clinical Practice Research Datalink to other health-related patient data: overview and implications. Eur J Epidemiol 2019;34:91-9.

33 Shephard EA, Stapley S, Neal RD, et al. Clinical features of bladder cancer in primary care. Br J Gen Pract 2012;62:e598-604.

34 Stapley S, Peters TJ, Neal RD, et al. The risk of oesophagogastric cancer in symptomatic patients in primary care: a large case-control study using electronic records. Br J Cancer 2013;108:25-31.

35 Taylor A, Stapley S, Hamilton W. Jaundice in primary care: a cohort study of adults aged $>45$ years using electronic medical records. Fam Pract 2012;29:416-20.

36 Price SJ, Shephard EA, Stapley SA, et al. Non-visible versus visible haematuria and bladder cancer risk: a study of electronic records in primary care. Br J Gen Pract 2014;64:e584-9. 
37 Din NU, Ukoumunne OC, Rubin G, et al. Age and gender variations in cancer diagnostic intervals in 15 cancers: analysis of data from the UK clinical practice research datalink. PLoS One 2015;10:e127717.

38 Mounce LTA, Price S, Valderas JM, et al. Comorbid conditions delay diagnosis of colorectal cancer: a cohort study using electronic primary care records. Br J Cancer 2017;116:1536-43.

39 Walker S, Hyde C, Hamilton W. Risk of breast cancer in symptomatic women in primary care: a case-control study using electronic records. Br J Gen Prac 2014;64:e788-93.

40 Burns EM, Rigby E, Mamidanna R, et al. Systematic review of discharge coding accuracy. J Public Health 2012;34:138-48.

41 Office of National Statistics. Cancer registration statistics QMI2016. Available: https://www.ons.gov.uk/peoplepopula tionandcommunity/healthandsocialcare/conditionsanddiseases/ methodologies/cancerregistrationstatisticsqmi [Accessed $23 \mathrm{Feb}$ 2021].

42 Merriel SWD, Turner EL, Walsh E, et al. Cross-sectional study evaluating data quality of the National Cancer Registration and Analysis Service (NCRAS) prostate cancer registry data using the cluster randomised trial of PSA testing for prostate cancer (CAP). BMJ Open 2017;7:e015994.

43 Møller H, Richards S, Hanchett N, et al. Completeness of case ascertainment and survival time error in English cancer registries: impact on 1-year survival estimates. Br J Cancer 2011;105:170-6.

44 Khan NF, Harrison SE, Rose PW. Validity of diagnostic coding within the general practice research database: a systematic review. Br J Gen Pract 2010;60:e128-36.

45 Herrett E, Thomas SL, Schoonen WM, et al. Validation and validity of diagnoses in the general practice research database: a systematic review. Br J Clin Pharmacol 2010;69:4-14.

46 Watson J, Nicholson BD, Hamilton W, et al. Identifying clinical features in primary care electronic health record studies: methods for codelist development. BMJ Open 2017;7:e019637.

47 Price S, Spencer A, Zhang X, et al. Trends in time to cancer diagnosis around the period of changing national guidance on referral of symptomatic patients: a serial cross-sectional study using UK electronic healthcare records from 2006-17. Cancer Epidemiol 2020;69:101805.

48 Abel G, Elliott MN. Identifying and quantifying variation between healthcare organisations and geographical regions: using mixed-effects models. BMJ Qual Saf 2019;28:bmjqs-2018-009165-8.

49 StataCorp. Stata statistical software: release 14. College Station, TX: StataCorp LP, 2015.

50 Dommett RM, Redaniel MT, Stevens MCG, et al. Features of childhood cancer in primary care: a population-based nested case-control study. Br J Cancer 2012;106:982-7.

51 Jones R, Latinovic R, Charlton J, et al. Alarm symptoms in early diagnosis of cancer in primary care: cohort study using general practice research database. BMJ 2007;334:1040.

52 Tate AR, Martin AGR, Ali A, et al. Using free text information to explore how and when GPs code a diagnosis of ovarian cancer: an observational study using primary care records of patients with ovarian cancer. BMJ Open 2011;1:e000025.

53 Lyratzopoulos G, Neal RD, Barbiere JM, et al. Variation in number of general practitioner consultations before hospital referral for cancer: findings from the 2010 National Cancer Patient Experience Survey in England. Lancet Oncol 2012;13:353-65.
54 Hamilton W, Lancashire R, Sharp D, et al. The importance of anaemia in diagnosing colorectal cancer: a case-control study using electronic primary care records. Br J Cancer 2008;98:323-7.

55 Jensen H, Tørring ML, Olesen F, et al. Cancer suspicion in general practice, urgent referral and time to diagnosis: a population-based GP survey and registry study. BMC Cancer 2014;14:636.

56 Ingeman ML, Christensen MB, Bro F, et al. The Danish cancer pathway for patients with serious non-specific symptoms and signs of cancer - a cross-sectional study of patient characteristics and cancer probability. BMC Cancer 2015;15:421.

57 Kidney E, Greenfield S, Berkman L, et al. Cancer suspicion in general practice, urgent referral, and time to diagnosis: a population-based GP survey nested within a feasibility study using information technology to flag-up patients with symptoms of colorectal cancer. BJGP Open 2017;1:bjgpopen17X101109.

58 Walter FM, Mills K, Mendonça SC, et al. Symptoms and patient factors associated with diagnostic intervals for pancreatic cancer (symptom pancreatic study): a prospective cohort study. Lancet Gastroenterol Hepatol 2016;1:298-306.

59 Walter FM, Emery JD, Mendonca S, et al. Symptoms and patient factors associated with longer time to diagnosis for colorectal cancer: results from a prospective cohort study. $\mathrm{Br} \mathrm{J}$ Cancer 2016;115:533-41.

60 Fleming ST, Pursley HG, Newman B, et al. Comorbidity as a predictor of stage of illness for patients with breast cancer. Med Care 2005;43:132-40.

61 Pearson C, Fraser J, Peake M, et al. Establishing populationbased surveillance of diagnostic timeliness using linked cancer registry and administrative data for patients with colorectal and lung cancer. Cancer Epidemiol $2019 ; 61: 111-8$.

62 Renzi C, Kaushal A, Emery J, et al. Comorbid chronic diseases and cancer diagnosis: disease-specific effects and underlying mechanisms. Nat Rev Clin Oncol 2019;16:746-61.

63 Forbes LJL, Warburton F, Richards MA, et al. Risk factors for delay in symptomatic presentation: a survey of cancer patients. Br J Cancer 2014;111:581-8.

64 Macleod U, Mitchell ED, Burgess C, et al. Risk factors for delayed presentation and referral of symptomatic cancer: evidence for common cancers. Br J Cancer 2009;101 Suppl 2:S92-101.

65 Verlinde E, De Laender N, De Maesschalck S, et al. The social gradient in doctor-patient communication. Int J Equity Health 2012;11:12.

66 Willems S, De Maesschalck S, Deveugele M, et al. Socio-economic status of the patient and doctor-patient communication: does it make a difference? Patient Educ Couns 2005;56:139-46.

67 Mercer SW, Higgins M, Bikker AM, et al. General practitioners' empathy and health outcomes: a prospective observational study of consultations in areas of high and low deprivation. Ann Fam Med 2016;14:117-24.

68 Amelung D, Whitaker KL, Lennard D, et al. Influence of doctor-patient conversations on behaviours of patients presenting to primary care with new or persistent symptoms: a video observation study. BMJ Qual Saf 2020;29:198-208.

69 Jiwa M, Saunders C. Fast track referral for cancer. British Medical Journal Publishing Group, 2007. 